\title{
Development and validation of rapid LC-MS with electrospray ionization for the quantification of pramipexole in human plasma
}

\author{
Petikam Lavudu ${ }^{1}$, Avula Prameela Rani ${ }^{2}$, Chandra Bala Sekharan ${ }^{3, *}$ \\ ${ }^{1}$ Department of Pharmaceutical Biotechnology, \\ Vishnu Institute of Pharmaceutical Education and Research, \\ Narsapur, Andhra Pradesh - 502313, India \\ *Tel: $+91-9848834447$ \\ ${ }^{2}$ University College of Pharmaceutical Sciences, Acharya Nagarjuna University, \\ Guntur, Andhra Pradesh - 522510, India \\ ${ }^{3}$ Department of Biotechnology, Jagarlamudi Kuppuswamy Choudary College, \\ Guntur, Andhra Pradesh - 522006, India \\ *E-mail address: balumphil@gmail.com
}

\begin{abstract}
A rapid, accurate and precise LC-MS method is described for the quantitative determination of pramipexole in human plasma matrix using ropinirole as internal standard. Pramipexole and ropinirole were extracted from plasma by liquid-liquid extraction technique. The method was validated over the concentration range of $100-2514 \mathrm{pg} / \mathrm{mL}$. The method was found to have acceptable accuracy, precision, linearity and selectivity. The mean extraction recovery from spiked plasma samples was in the range of 79.415-87.00\%. The intra-day accuracy of the assay ranged from 98.924 to $112.236 \%$ and intra-day precision ranged from 3.489 to $6.756 \%$. Inter-day accuracy and precision results for quality control samples ranged between 100.340 and $107.443 \%$ of nominal and precision is observed to be $3.970-5.714 \%$. The pramipexole was found to be stable after several stability studies. The proposed method yielded a quick, simple and reliable protocol for estimating pramipexole concentrations in human plasma.
\end{abstract}

Keywords: Pramipexole; LC-MS; human plasma; bioanalytical method

\section{INTRODUCTION}

Pramipexole (PPE) is a aminothiazole dopamine agonist approved in the US (1997) for management of the symptoms of early and advance stages of Parkinson's disease [1-3] and restless legs syndrome [4,5]. Preferential affinity of PPE for the $\mathrm{D}_{3}$ receptor could contribute to efficacy in the treatment of both the motor and psychiatric symptoms of Parkinson's 
disease. The precise mechanism of action of PPE in the treatment of Parkinson's disease is unknown, although it is believed to be related to its ability to stimulate dopamine receptors in the striatum.

Generally PPE is administered three times daily (dosage: $0.375-1.5 \mathrm{mg} /$ day) for Parkinson's disease. Single daily administration (dosage: $0.125-0.50 \mathrm{mg} / \mathrm{day}$ ) is suggested for restless legs syndrome. Accumulation of the drug can occur in patients with renal dysfunction as PPE is eliminated primarily by renal clearance. Therefore dosage reduction must be envisaged. It is essential to develop sensitive and rapid bioanalytical method for the quantification of PPE in biological matrices like urine and human plasma to minimize the risk of PPE accumulation and to lessen the occurrence of adverse effects.

Lau et al., [6] developed a HPLC method for the assay of PPE in human plasma and urine. Separation is achieved by ion-pair chromatography on a Zorbax $\mathrm{Rx} \mathrm{C}_{8}$ column with electrochemical detection at $0.6 \mathrm{~V}$ for plasma and ultraviolet detection at $286 \mathrm{~nm}$ for urine. The retention time of PPE is approximately $14.4 \mathrm{~min}$. Lau et al., [7] proposed a sensitive HPLC with atmospheric pressure chemical ionization tandem mass spectrometry for estimating PPE in human plasma. The chromatographic analysis time was $<5 \mathrm{~min}$, but the method used a large volume $(1 \mathrm{~mL})$ of plasma for processing. Further more, the method was applied to study the pharmacokinetics of PPE administered to only one human volunteer $(0.25$ mg oral dose).

A high performance liquid chromatography/electrospray ionization tandem mass spectrometry method has been proposed by Nirogi etal., [8] for the estimation of PPE in human plasma. This method has high throughput but is less sensitive. Bharathi etal., [9] have developed a highly sensitive and rapid LC-MS/MS method for determination of PPE in 0.5 $\mathrm{mL}$ human plasma. Solid-phase extraction was applied to extract PPE from human plasma. The chromatographic run time was $3.0 \mathrm{~min}$. Uma etal., [10] developed a highly sensitive LCMS method for the estimation of PPE in $0.5 \mathrm{~mL}$ human Plasma. PPE and internal standard were ionized by positive-ion electro spray ionization mode and solid phase extraction technique was used for extraction of PPE from plasma using Strata-X $33 \mu \mathrm{m}$ cartridges. The method was not completely validated.

Due to the drawbacks or disadvantages in the earlier reported bioanalytical methods, there is a need to develop and validate a sensitive and rapid bioanalytical method for the assay of PPE. The present paper describes the development and validation of a sensitive and rapid LC-MS method for the bioanalysis of PPE in human plasma.

\section{EXPERIMENTAL}

\section{1. Instrumentation}

1. The chromatographic experiments were performed on a Shimadzu HPLC system (Shimadzu, Kyoto, Japan) consisting of a LC-10ADvp pump, a SCL-10Avp system controller (accompanied by an auto sampler), a CTO-10Avp column oven, an FCV10ALvp low pressure gradient unit and DGU- 14A degasser.

2. Mass spectrometric detection was performed on an API 4000 triple quadrupole tandem mass spectrometer (Applied Biosystems MDS SCIEX, CA, USA) equipped with an electro spray ionization source in positive ionization mode.

3. Analyst software version 1.4.2 (Applied Biosystems MDS SCIEX, CA, USA) was used for data processing. 
4. Chromatographic separation of PPE and internal standard, ropinirole, was carried out using a Zorbax SB-C18, $3.5 \mu \mathrm{m}$ particle size, 4.6 x $150 \mathrm{~mm}$ analytical column.

5. The samples were weighed by Sartorius analytical balance (Goettingen, Germany).

\section{2. Chemicals}

Pramipexole and ropinirole were obtained from Matrix laboratories, Hyderabad, India. Ammonium formate (reagent grade) was obtained from sd-fine chemicals (Mumbai, India). HPLC grade acetonitrile, methanol, ethyl acetate, n-hexane, formic acid and ammonia were obtained from Merck Specialities Pvt Ltd (Mumbai, India).

\section{3. Preparation of solutions}

\section{3. 1. Diluent solution}

Prepared by mixing water and methanol in the ratio of 50:50 v/v.

\section{3. 2. Extraction solvent}

Prepared by mixing ethyl acetate and $n$-hexane in the ratio of 90:10 v/v.

\section{3. 3. Rinsing solution}

Prepared by mixing water and acetonitrile in the ratio of 50:50 v/v.

\section{3. 4. Mobile phase}

The mobile phase used for analysis was prepared by mixing $10 \mathrm{mM}$ ammonium formate and acetonitrile in the ratio, 40:60 $v / v$. Ten $\mathrm{mM}$ ammonium formate was prepared by mixing $0.63 \mathrm{mg}$ of ammonium formate and $2 \mathrm{~mL}$ of formic acid in a total volume of $1000 \mathrm{~mL}$.

Diluent solution, extraction solvent, rinsing solution and mobile phase are used within 4 days of preparation.

\section{3. 5. Stock and working standard solutions}

The stock standard solution of PPE $(1 \mathrm{mg} / \mathrm{mL})$ was prepared by dissolving $10 \mathrm{mg}$ of PPE in methanol in a $10 \mathrm{~mL}$ volumetric flask. Working standard solution of PPE $(10 \mathrm{ng} / \mathrm{mL})$ was prepared by suitably diluting the PPE stock standard solution with diluent. The stock standard solution $(1 \mathrm{mg} / \mathrm{mL})$ of internal standard (ISTD), ropinirole was prepared by dissolving $10 \mathrm{mg}$ of ISTD in methanol in a $10 \mathrm{~mL}$ volumetric flask. Working standard solution of ISTD $(1 \mathrm{ng} / \mathrm{mL})$ was prepared by suitably diluting the ropinirole stock standard solution with diluent.

These standard solutions were stored at $2-8{ }^{\circ} \mathrm{C}$ in a refrigerator (LG Electronics India Pvt. Ltd, New Delhi, India) until analysis. Before use these solutions are brought to room temperature.

\subsection{Spiked plasma calibration curve standards}

Pramipexole calibration curve standards with concentrations 100, 222, 317, 635, 1155, 1674, 2263 and $2514 \mathrm{pg} / \mathrm{mL}$ in drug free human plasma were prepared by spiking with appropriate volume of PPE standard working solution. 


\subsection{Spiked plasma quality control samples}

Four quality control samples with concentrations 100, 264, 825 and $2230 \mathrm{pg} / \mathrm{mL}$ PPE were prepared by spiking drug free human plasma with appropriate volume of PPE standard working solution and they are treated as LLOQ, LQC, MQC and HQC, respectively.

Calibration curve standards and quality control samples were stored at $-20{ }^{\circ} \mathrm{C}$ in a deep freezer (Haier, Delhi, India) until analysis. Before use these samples are brought to room temperature.

\section{4. Chromatographic conditions}

The Zorbax SB-C18 (4.6 x $150 \mathrm{~mm}, 3.5 \mu \mathrm{m}$ particle size) was selected as the analytical column. The mobile phase was composed of $10 \mathrm{mM}$ ammonium formate and acetonitrile in the ratio of 40:60 $(\mathrm{v} / \mathrm{v})$. The flow rate of the mobile phase was set at $0.5 \mathrm{~mL} / \mathrm{min}$ (split ratio 40:60). The injection volume was $20 \mu \mathrm{L}$. The column oven and auto sampler temperature was set at $40 \pm 1{ }^{\circ} \mathrm{C}$ and $10 \pm 1{ }^{\circ} \mathrm{C}$, respectively. Ropinirole was found to be apt internal standard interms of chromatography and extractability. The run time was $3 \mathrm{~min}$ and $500 \mu \mathrm{L}$ of rinsing solution was used during rinsing cycle or wash cycle.

\section{5. Mass spectrometer conditions}

Electrospray ionization source in positive ionization mode with multiple reaction monitoring (MRM) was used for the detection. For PPE and ISTD the $[\mathrm{M}+\mathrm{H}]^{+}$ions were monitored at $\mathrm{m} / \mathrm{z} 212.10$ and $\mathrm{m} / \mathrm{z} 261.20$ as the precursor ion, and a fragment at $\mathrm{m} / \mathrm{z} 153.10$ and $m / z 114.20$ as the product ion, respectively. Mass parameters were optimized as ion source temperature $500{ }^{\circ} \mathrm{C}$, nebulizer gas 45 (nitrogen) psi, heater gas 50 (nitrogen) psi, curtain gas 20 (nitrogen) psi, collision gas 20 (nitrogen) psi, ionization voltage $5500 \mathrm{~V}$. Entrance potential, collision cell exit potential and dwell time per transition were $10 \mathrm{~V}, 10 \mathrm{~V}$ and 400 milliseconds, respectively for PPE and ISTD. The declustering potential is $40 \mathrm{~V}$ for PPE and $60 \mathrm{~V}$ for ISTD. The collision energy is $19 \mathrm{eV}$ and $26 \mathrm{eV}$ for PPE and ISTD, respectively.

\section{6. Processing of plasma sample}

Pramipexole and ropinirole were extracted from plasma samples by using liquid-liquid extraction technique. All frozen, calibration curve standards and quality control samples were thawed at room temperature and homogenized with a vortex shaker (Spinix, Mumbai, India). Five hundred $\mu \mathrm{L}$ plasma samples in polypropylene tubes were spiked with $50 \mu \mathrm{L}$ of ISTD standard solution $(1 \mathrm{ng} / \mathrm{mL})$.

The samples were vortexed for 30 seconds. To all the tubes $100 \mu \mathrm{L}$ of $50 \%$ ammonia in water was added and again vortexed for few seconds. Then $2.5 \mathrm{~mL}$ of extraction solvent [Ethyl acetate: $n$-Hexane $(90: 10 v / v)$ ] was added, closed with tight caps and vortexed for 10 min followed by centrifugation at $4500 \mathrm{rpm}$ at $5{ }^{\circ} \mathrm{C}$ for $10 \mathrm{~min}$.

The upper organic layer was transferred into another polypropylene tubes and evaporated, in a nitrogen evaporator (Caliper Lifesciences, Hopkinton, Massachusetts), to dryness under nitrogen atmosphere at $40{ }^{\circ} \mathrm{C}$ temperature.

After evaporation was completed, samples were reconstituted with $300 \mu \mathrm{L}$ of mobile phase and vortexed for 30 seconds. The samples were transferred into auto sampler vials for injection into LC-MS/MS system. 


\section{7. Method validation}

The method was validated as per the guidelines of United States Food and Drug Administration for validation of bioanalytical methods [11].

\subsection{Method selectivity}

The method selectivity was assessed by the comparison of chromatograms of six different blank human plasma with the corresponding chromatograms of plasma samples spiked at LLOQ $(100 \mathrm{pg} / \mathrm{mL})$ level of the PPE and $1 \mathrm{ng} / \mathrm{mL}$ of the ISTD using the proposed extraction procedure, chromatography and mass spectrometry conditions. The acceptance criteria for area of interference compounds in blank human plasma are $\geq 20 \%$ in comparison to the spiked LLOQ and $\leq 5 \%$ in comparison to internal standard.

\subsection{Linearity}

The performance of the method was assessed by determining the linearity. The linearity of the method was determined by preparing three calibration curves with eight different concentrations 100, 222, 317, 635, 1155, 1674, 2263 and $2514 \mathrm{pg} / \mathrm{mL}$ PPE. The peak area ratios of the PPE to ISTD were calculated. The calibration curves were obtained by fitting these ratios as a function of corresponding concentrations using weighted $\left(1 / \mathrm{x}^{2}\right)$ least square linear regression. The lowest concentration of the PPE $(100 \mathrm{pg} / \mathrm{mL})$ on the calibration curve was considered as LLOQ with acceptable accuracy and precision. The acceptance criteria of back calculated standard concentration was lower than $15 \%$ deviation from nominal concentration and lower than $20 \%$ deviation from nominal concentration at the LLOQ level. The acceptance criterion for correlation coefficient $\left(\mathrm{r}^{2}\right)$ was 0.99 or more.

\section{7. 3. Accuracy and precision}

The precision and accuracy of the method were assessed under repeatable (intra-day) and reproducible (inter-day) circumstances. The intra- and inter-day precision and accuracy were evaluated at four different concentration levels [100 pg/mL (LLOQ), $264 \mathrm{pg} / \mathrm{mL}$ (LQC), $825 \mathrm{pg} / \mathrm{mL}$ (MQC) and $2230 \mathrm{pg} / \mathrm{mL}$ (HQC)]. For intra-day precision and accuracy, each quality control sample was analyzed six times on the same day whereas for inter-day precision and accuracy same samples were analyzed on three different days. The precision and accuracy of the method was expressed as percentage of coefficient of variation (CV) and percentage recovery, respectively. The intra- \& inter-day accuracy determined at each concentration level should not exceed $15 \%$ of nominal concentration for all the quality control samples except for LLOQ, where it should not exceed $20 \%$. The intra- \& inter-day precision for all the quality control samples should be $<15 \%$ of $\mathrm{CV}$.

\section{7. 4. Extraction recovery}

The extraction recovery of PPE and ISTD were evaluated by comparing peak area of plasma spiked with PPE and ISTD prior to extraction with the peak area of plasma spiked with PPE and ISTD after the extraction. The extraction recovery of PPE was evaluated at three different concentration levels [264 pg/mL (LQC), $825 \mathrm{pg} / \mathrm{mL}$ (MQC) and $2230 \mathrm{pg} / \mathrm{mL}$ (HQC)] and extraction recovery of ISTD was evaluated at a concentration of $1 \mathrm{ng} / \mathrm{mL}$. The recovery of the analyte and ISTD need not be $100 \%$, but the extent of recovery of an analyte and ISTD should be consistent, precise and reproducible. 


\section{7. 5. Stability of drug in stock solution}

The stability of the PPE in solution was investigated in two ways: short term stability and long term stability. For short term stability, stock solutions of PPE and ISTD were prepared and left at room temperature (stability samples) for $10 \mathrm{hrs}$. The freshly prepared stock solution was used as comparison sample. For long term stability, stock solutions of PPE and ISTD were prepared and stored in refrigerator below $10{ }^{\circ} \mathrm{C}$ (stability samples) for 8 days. On the day of analysis, freshly prepared stock solution was used as comparison sample. The short-term and long term stock solution stability of PPE and ISTD in diluent solution was successfully assessed by comparing mean responses of six replicates of stability samples versus six replicates of comparison samples. For both the stability studies, the samples were considered stable in stock solution if the deviation from the mean peak area is within $\pm 15 \%$.

\section{7. 6. Stability of drug in human plasma}

The stability of the PPE in human plasma was investigated in five ways: Freeze thaw stability, Bench top stability, Long term stability, In-injector stability and Effect of anticoagulant. All the stability studies were assessed by analyzing six replicates of LQC (264 $\mathrm{pg} / \mathrm{mL})$ and HQC (2230 pg/mL).

Freeze thaw stability was determined after six cycles of freeze-thaw, bench top stability was assessed after keeping the plasma samples at room temperature for $7 \mathrm{hrs}$, long term stability was assessed after storage of the test samples at $-70{ }^{\circ} \mathrm{C}$ for 30 days, in-injector stability was determined by storing the reconstituted quality control samples for $48 \mathrm{hrs}$ at 10 ${ }^{\circ} \mathrm{C}$ in auto sampler before being analyzed and effect of anticoagulant was assessed by comparing the percentage stability of PPE in human plasma containing ethylenediaminetetraacetic acid with human plasma containing citrate phosphate dextrose adenine.

The stability samples were run along with the freshly spiked calibration curve. The values were calculated against calibration curve of the day. The freshly prepared quality control samples (LQC and HQC) were used as comparison sample. The stability of the PPE in human plasma was successfully assessed by comparing mean value of six replicates of stability samples with six replicates of comparison samples. The samples were considered stable in human plasma at each concentration level if the deviation from the mean calculated concentration of quality control samples were within $\pm 15 \%$.

\section{RESULTS AND DISCUSSION}

\section{1. Method development}

\section{1. 1. Optimization of mass spectroscopy conditions}

The LC-MS/MS operating parameters were carefully optimized for the sensitive and selective determination of PPE. A standard solution $(1 \mathrm{ng} / \mathrm{mL})$ of PPE and the ISTD were directly infused along with the mobile phase into the mass spectrometer with ESI as the ionization source and tuned initially in both positive and negative ESI modes. The outcomes indicated that positive ESI mode was found to be more sensitive than negative ESI mode. The mass spectra for PPE and ISTD revealed peaks at $\mathrm{m} / \mathrm{z} 212.10$ and 261.20, respectively, as protonated molecular ions $[\mathrm{M}+\mathrm{H}]^{+}$. The product ion mass spectrum for PPE shows the formation of major fragment ion at $\mathrm{m} / \mathrm{z} 153.10$. For ISTD, the fragment at $\mathrm{m} / \mathrm{z} 114.20$ was dominant and was consequently used for quantification. 
The mass spectrometric parameters, such as ion source temperature, ion source gas 1 (nebulizer gas), ion source gas 2 (heater gas), curtain gas, collision gas, ionization voltage and collision energy were optimized to obtain the optimum intensity of deprotonated molecules of PPE and ISTD. The results are summarized in Tables 1 and 2.

Table 1. Optimized source gas parameters of the proposed LC-MS method.

\begin{tabular}{|c|c|}
\hline Parameter & Value \\
\hline Curtain gas (nitrogen) (psi) & 20 \\
\hline Collision (nitrogen) (psi) & 6 \\
\hline Gas1 (nebulizer gas) (psi) & 45 \\
\hline Gas2 (heater gas) (psi) & 50 \\
\hline Ion source temperature $\left({ }^{0} \mathrm{C}\right)$ & 500 \\
\hline Ionization voltage $(\mathrm{V})$ & 5500 \\
\hline
\end{tabular}

Table 2. Optimized compound parameters of the proposed LC-MS method.

\begin{tabular}{|c|c|c|}
\hline Parameters & PPE & ISTD \\
\hline Declustering potential (V) & 40 & 60 \\
\hline Entrance potential (V) & 10 & 10 \\
\hline Collision energy (eV) & 19 & 26 \\
\hline Collision cell exit potential (V) & 10 & 10 \\
\hline Dwell time (millisecond) & 400 & 400 \\
\hline
\end{tabular}

\section{1. 2. Optimization of chromatography conditions}

To achieve the effective chromatographic resolution of PPE and ISTD, various mixture(s) of organic solvents such as acetonitrile and methanol along with $10 \mathrm{mM}$ ammonium formate with altered flow rates (in the range of $0.20-1.0 \mathrm{~mL} / \mathrm{min}$ ) were tested.

The best resolution of peaks was achieved with an isocratic elution by the mobile phase consisting of acetonitrile and $10 \mathrm{mM}$ ammonium formate in the ratio of 60:40 $(\mathrm{v} / \mathrm{v})$ at a flowrate of $0.5 \mathrm{~mL} / \mathrm{min}$, on Zorbax SB-C18 analytical column $(3.5 \mu \mathrm{m}$ particle size, $4.6 \times 150$ $\mathrm{mm})$.

The column oven temperature was maintained at $40{ }^{\circ} \mathrm{C}$. Under the optimized chromatographic conditions, the retention times of PPE and the ISTD were around 1.344 and $1.534 \mathrm{~min}$, respectively. 


\section{1. 3. Selection of extraction solvent}

Liquid-liquid extraction can be helpful in creating a clean sample and avoiding the insertion of non volatile materials onto the HPLC column and mass spectrophotometer system. Clean samples are essential for minimizing ion suppress ion and matrix effect in bioanalytical methods. Acetonitrile : dichloromethane, $n$-hexane : dichloromethane, $n$-hexane : dichloromethane : ethyl acetate and ethyl acetate : $n$-hexane mixtures were tried with different percentages as a solvent for the extraction of PPE and ISTD from the plasma. A mix of ethyl acetate : $n$-hexane in the proportion of 90:10 $(\mathrm{v} / \mathrm{v})$ was found to be optimal, which can produce a clean chromatogram for blank plasma blank and maximum recovery. As a result, this solvent mixture was preferred as a solvent for extraction.

\section{1. 4. Selection of internal standard}

Selecting the appropriate ISTD is an important aspect to achieving acceptable method performance, especially with bioanalytical methods, where matrix effects can contribute to poor analytical results. Therefore, ropinirole was selected as apt internal standard, which is relevant to PPE. In addition, ropinirole retention behavior is similar to that of the PPE. Clean chromatograms were obtained and no significant direct interferences in multiple reaction monitoring channels at the relevant retention times were observed.

\section{2. Method validation}

\section{2. 1. Method selectivity}

No peaks were observed in blank plasma at the corresponding retention time of PPE $(1.344 \mathrm{~min})$ and internal standard $(1.534 \mathrm{~min})$. This suggests that there was no interference from endogenous substances present in the plasma and the method was found to be selective enough for the determination of PPE. The chromatograms of PPE and internal standard for blank plasma, showing no interference at the retention time of the PPE and the internal standard, plasma spiked at the LLOQ level of PPE are shown in Fig. 1 and 2.

\section{2. 2. Linearity}

Table 3. Back calculated concentrations for calibration curve standards of PPE.

\begin{tabular}{|c|c|c|c|c|}
\hline \multirow{2}{*}{$\begin{array}{c}\text { Calibration } \\
\text { Standard }\end{array}$} & \multicolumn{2}{|c|}{ Concentration of PPE $(\mathbf{p g} / \mathbf{m L})$} & \multirow{2}{*}{ \pm SD } & \multirow{2}{*}{ CV } \\
\cline { 2 - 3 } & Nominal & Mean calculated* & & \\
\hline S1 & 100 & 98.736 & 1.93 & 1.95 \\
\hline S2 & 222 & 233.633 & 15.83 & 6.78 \\
\hline S3 & 317 & 313.637 & 5.85 & 1.86 \\
\hline S4 & 635 & 614.021 & 30.44 & 4.96 \\
\hline S5 & 1155 & 1172.747 & 24.34 & 2.08 \\
\hline S6 & 1674 & 1623.062 & 73.01 & 4.50 \\
\hline S7 & 2263 & 2215.351 & 67.52 & 3.05 \\
\hline S8 & 2514 & 2633.206 & 167.81 & 6.37 \\
\hline
\end{tabular}

* mean of three determinations 


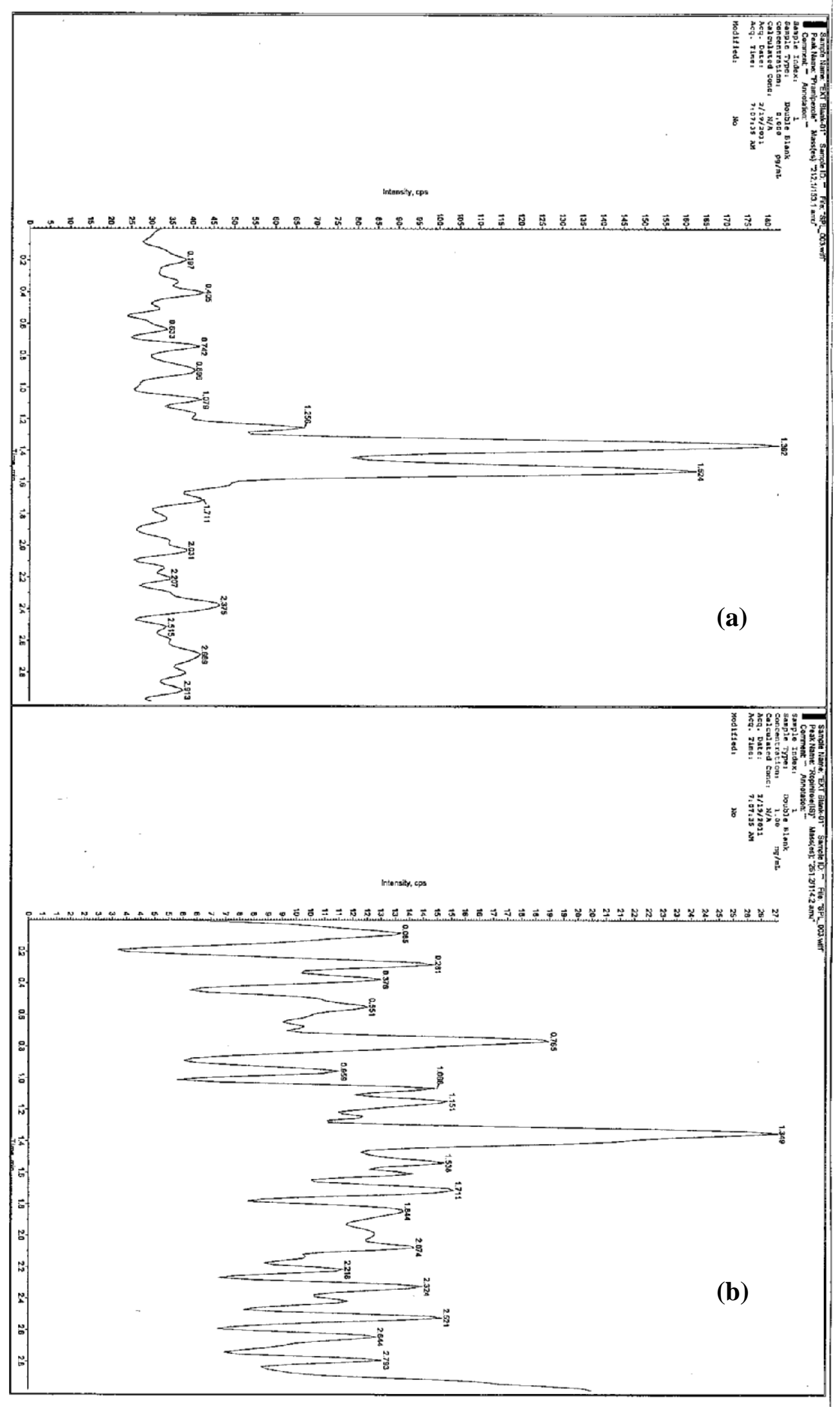

Fig. 1. Chromatogram of (a) blank plasma for PPE (b) blank plasma for ISTD. 


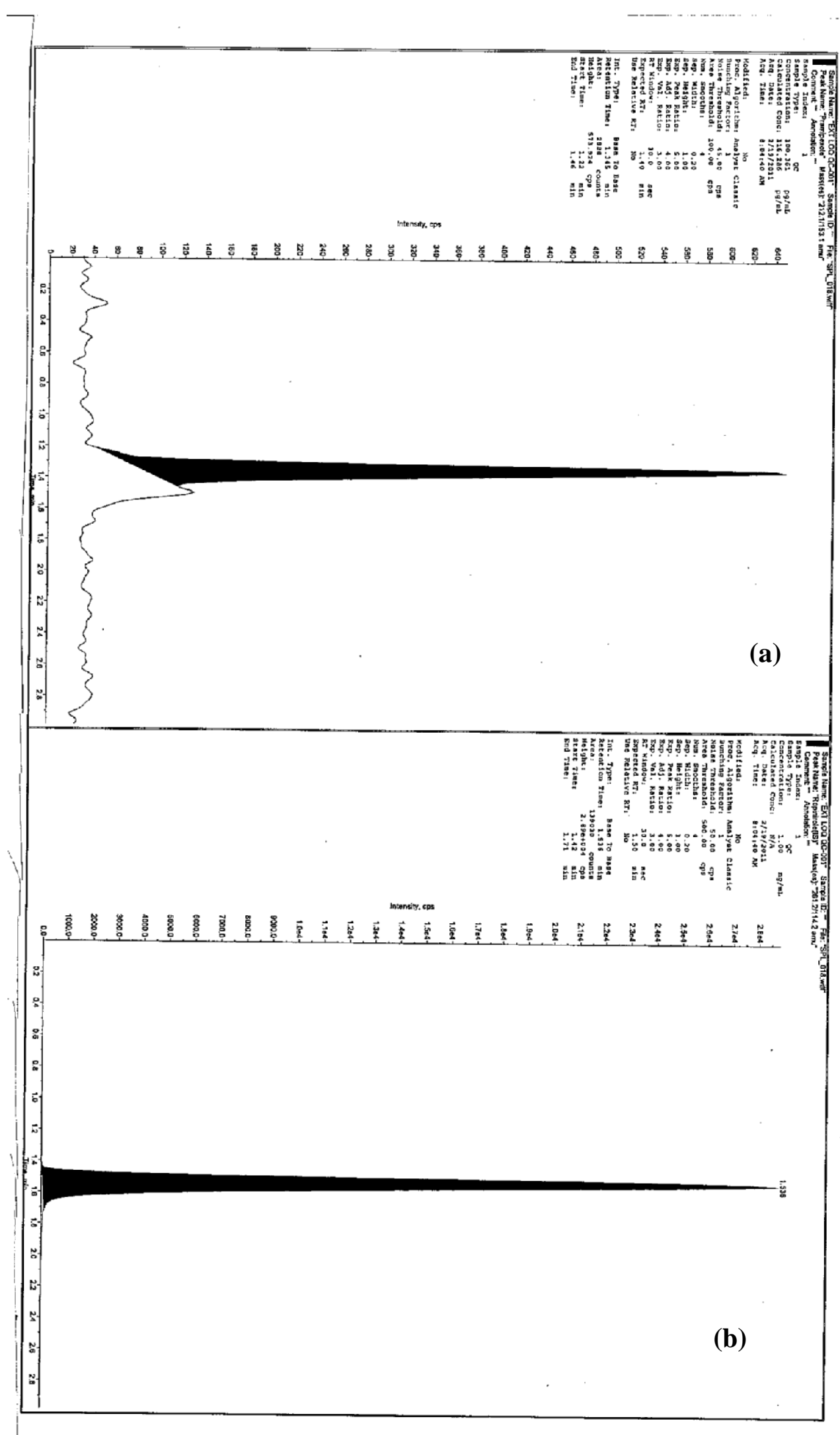

Fig. 2. Chromatogram of (a) LLOQ level of PPE (b) ISTD. 
The linearity was calculated by using weighted least squares regression analysis $\left(1 / \mathrm{X}^{2}\right)$ of PPE/ ISTD peak area ratios vs PPE concentration. The method was linear over the PPE concentration range from 100-2514 pg/mL. The calibration curve showed good linearity with correlation coefficient value of 0.9966 . The calibration curve had a regression equation of $y=$ $0.000196 \mathrm{x}+-0.00198$, where $\mathrm{y}$ is the peak area ratio of PPE to ISTD and $\mathrm{x}$ is the plasma concentration of PPE. The back calculated concentration of calibration samples showed good precision \& accuracy and they are within the acceptance limit (Table 3). The lowest point $(100 \mathrm{pg} / \mathrm{mL})$ on the standard curve was accepted as LLOQ.

\section{2. 3. Accuracy and precision}

The percentage recovery and percentage coefficient of variation values for the assays in accuracy and precision study, respectively were calculated. The results are summarized in Table 4. The intra-day precision and accuracy were in the range of 3.489-6.756 \% and 98.924$112.236 \%$, respectively. Like wise the inter-day precision and accuracy ranged from 3.970$5.714 \%$ and $100.340-107.443 \%$, respectively. The precision and accuracy values are within the acceptable limit and indicating that the developed method was sufficiently precise and accurate.

Table 4. Intra- and Inter-day precision and accuracy of the proposed LC-MS method.

\begin{tabular}{|c|c|c|c|c|}
\hline \multirow{2}{*}{ Level } & \multicolumn{2}{|c|}{ Concentration of PPE $(\mathrm{pg} / \mathrm{mL})$} & \multirow{2}{*}{$\begin{array}{c}\text { Recovery } \\
(\%)\end{array}$} & \multirow{2}{*}{$\begin{array}{l}\text { CV } \\
(\%)\end{array}$} \\
\hline & Nominal & Found $* \pm$ SD & & \\
\hline \multicolumn{5}{|c|}{ Intra-day } \\
\hline LLOQ & 100 & $112.236 \pm 5.532$ & 112.236 & 4.928 \\
\hline LQC & 264 & $281.561 \pm 19.024$ & 106.651 & 6.756 \\
\hline MQC & 825 & $836.785 \pm 47.285$ & 101.428 & 5.650 \\
\hline $\mathrm{HQC}$ & 2230 & $2206.021 \pm 76.976$ & 98.924 & 3.489 \\
\hline \multicolumn{5}{|c|}{ Inter-day } \\
\hline LLOQ & 100 & $107.443 \pm 5.765$ & 107.443 & 5.365 \\
\hline LQC & 264 & $280.707 \pm 16.042$ & 106.328 & 5.714 \\
\hline MQC & 825 & $835.477 \pm 41.474$ & 101.269 & 4.964 \\
\hline $\mathrm{HQC}$ & 2230 & $2237.603 \pm 88.836$ & 100.340 & 3.970 \\
\hline
\end{tabular}

* Average of six determinations

\section{2. 4. Extraction recovery}

The extraction yield was calculated by dividing the mean peak area of the plasma sample spiked with PPE and ISTD prior to extraction by the corresponding mean peak area of the plasma sample spiked with PPE and ISTD after the extraction. The extraction recovery of the PPE at LQC, MQC and HQC levels was $87.0 \%, 84.499 \%$ and $82.08 \%$, respectively (Table 5).

The recovery of ISTD was $79.415 \%$ (Table 5). These results indicate that the recovery of PPE and ISTD using liquid-liquid extraction technique by extraction solvent, ethyl acetate and $n$-hexane $(90: 10 v / v)$, was satisfactory, consistent, precise and reproducible. 
Table 5. Extraction recovery of PPE and ISTD.

\begin{tabular}{|c|c|c|c|c|c|}
\hline Level & $\begin{array}{c}\text { Concentration } \\
(\mathrm{pg} / \mathrm{mL})\end{array}$ & Drug spiked & Peak area* \pm SD & $\begin{array}{l}\text { CV } \\
(\%)\end{array}$ & $\begin{array}{c}\text { Recovery } \\
(\%)\end{array}$ \\
\hline \multirow{2}{*}{ LQC } & \multirow{2}{*}{264} & Before extraction & $7403.6 \pm 488.33$ & 6.6 & \multirow{2}{*}{87.00} \\
\hline & & After extraction & $8509.7 \pm 748.01$ & 8.8 & \\
\hline \multirow{2}{*}{ MQC } & \multirow{2}{*}{825} & Before extraction & $20177.0 \pm 1512.35$ & 7.5 & \multirow{2}{*}{84.499} \\
\hline & & After extraction & $23878.2 \pm 571.72$ & 2.4 & \\
\hline \multirow{2}{*}{ HQC } & \multirow{2}{*}{2230} & Before extraction & $60435.7 \pm 3186.02$ & 5.3 & \multirow{2}{*}{82.080} \\
\hline & & After extraction & $97351.2 \pm 2426.13$ & 2.5 & \\
\hline \multirow{2}{*}{ ISTD } & \multirow{2}{*}{1} & Before extraction & $135125.6 \pm 8260.24$ & 6.1 & \multirow{2}{*}{79.415} \\
\hline & & After extraction & $212746.7 \pm 13969.10$ & 6.6 & \\
\hline
\end{tabular}

* Average of six determinations

\section{2. 5. Stability of drug in stock solution}

The results are summarized in Table 6. The percentage deviation for the mean peak area of PPE and ISTD left at room temperature for $10 \mathrm{hrs}$ was found to be $-7.07 \%$ and $-0.719 \%$, respectively. The percentage deviation for the mean peak area of PPE and ISTD stored in refrigerator below $10{ }^{\circ} \mathrm{C}$ for 8 days was found to be $-2.013 \%$ and $-8.864 \%$, respectively. This is within the acceptance range of $\pm 15 \%$. Results indicate that PPE and ISTD were stable for least $10 \mathrm{hrs}$ at room temperature and for 8 days when stored in refrigerator below $10^{\circ} \mathrm{C}$.

Table 6. Short term and long term stability of PPE and ISTD in stock solution.

\begin{tabular}{|c|c|c|c|c|}
\hline Drug & Type of sample & Peak area* & Stability (\%) & Deviation (\%) \\
\hline \multirow{2}{*}{ PPE } & Stability & 22060.5 & \multirow{2}{*}{92.930} & \multirow{2}{*}{-7.07} \\
\hline & Comparison & 23738.7 & & \\
\hline \multirow{2}{*}{ ISTD } & Stability & 217096.7 & \multirow{2}{*}{99.821} & \multirow{2}{*}{-0.719} \\
\hline & Comparison & 217485.7 & & \\
\hline \multirow{2}{*}{ PPE } & Stability & 23156.5 & \multirow{2}{*}{97.984} & \multirow{2}{*}{-2.016} \\
\hline & Comparison & 23632.8 & & \\
\hline \multirow{2}{*}{ ISTD } & Stability & 234919.2 & \multirow{2}{*}{91.136} & \multirow{2}{*}{-8.864} \\
\hline & Comparison & 257765.5 & & \\
\hline
\end{tabular}

* Average of six determinations

\section{2. 6. Stability of drug in human plasma}

The stability results of freeze thaw, bench top, long term, in-injector and effect of anticoagulant are summarized in Table 7. When PPE stability at the LQC and HQC concentrations was evaluated after six freeze thaw cycles, the differences from freshly prepared quality control samples was about $1.774 \%$ and $4.593 \%$, respectively. When bench top stability at the LQC and HQC concentrations at room temperature for $7 \mathrm{hrs}$ was measured the differences from freshly prepared quality control samples were $1.609 \%$ and $-3.681 \%$, respectively. 
Table 7. Stability of PPE in human plasma.

\begin{tabular}{|c|c|c|c|c|c|c|c|c|c|}
\hline 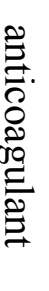 & 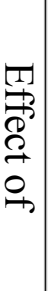 & 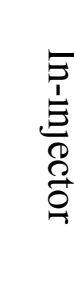 & 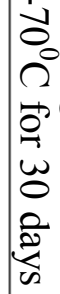 & 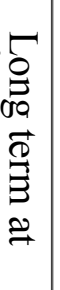 & $\begin{array}{l}\text { Th } \\
0 \\
0 \\
0 \\
0 \\
0\end{array}$ & & 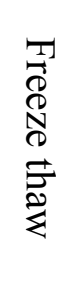 & 产 & \\
\hline 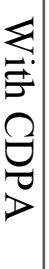 & 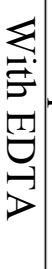 & 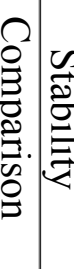 & 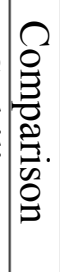 & 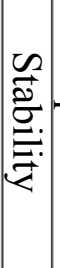 & 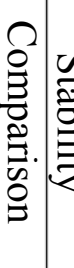 & 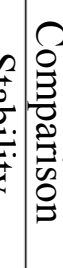 & | & \multicolumn{2}{|l|}{ 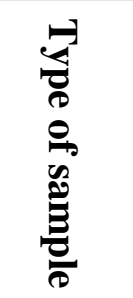 } \\
\hline 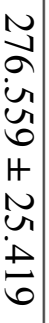 & 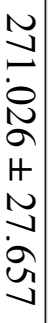 & 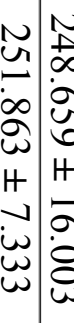 & 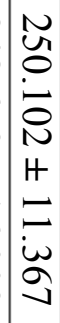 & 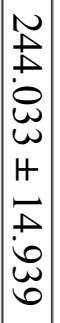 & 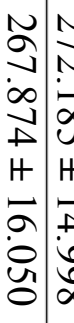 & 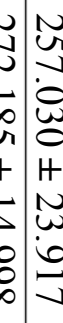 & 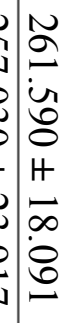 & 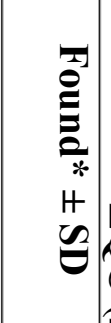 & مُ \\
\hline 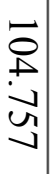 & $\begin{array}{l}\vec{\sigma} \\
\hat{N} \\
2 \\
\end{array}$ & $\frac{\infty}{\infty}$ & & $\begin{array}{l}0 \\
\text { v } \\
\dot{u} \\
\vec{w}\end{array}$ & $\begin{array}{l}a \\
\dot{g} \\
\dot{g}\end{array}$ & & 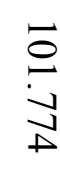 & 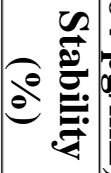 & $\frac{8}{ \pm}$ \\
\hline 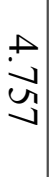 & $\begin{array}{l}n \\
\stackrel{\Omega}{\Omega}\end{array}$ & $\frac{1}{i}$ & & $\begin{array}{l}\stackrel{1}{N} \\
\stackrel{N}{N}\end{array}$ & g. & & $\underset{\perp}{\vec{D}}$ & 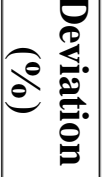 & \\
\hline 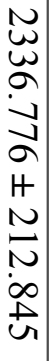 & $\begin{array}{l}N \\
N \\
\tilde{O} \\
\infty \\
\infty \\
\infty \\
H \\
N \\
\omega \\
\omega \\
\dot{b} \\
\dot{D}\end{array}$ & 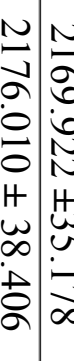 & 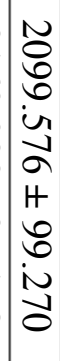 & 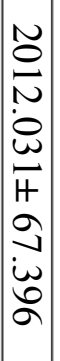 & 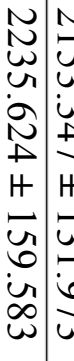 & 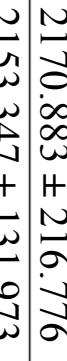 & 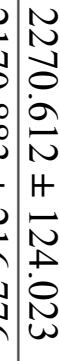 & 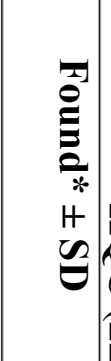 & 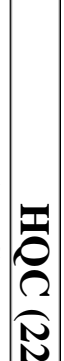 \\
\hline $\begin{array}{l}\vec{D} \\
\stackrel{+}{\sim} \\
\infty \\
\infty \\
\infty\end{array}$ & $\begin{array}{c}\overrightarrow{0} \\
\vdots \\
\omega \\
\infty \\
+ \\
+\end{array}$ & $\bar{\Omega}$ & & $\begin{array}{l}0 \\
u \\
\infty \\
\text { ర } \\
0\end{array}$ & $\begin{array}{l}b \\
i \\
b\end{array}$ & & $\begin{array}{l}\overrightarrow{0} \\
+ \\
\text { in } \\
\omega\end{array}$ & 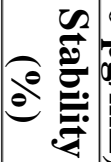 & 总 \\
\hline & $\begin{array}{l}\underset{\sim}{\omega} \\
\infty \\
+\end{array}$ & $\underset{i}{\stackrel{\alpha}{c}}$ & & $\overline{0}$ & 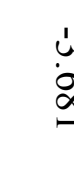 & مِ & 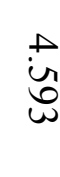 & (2) & \\
\hline
\end{tabular}


When PPE stability in the human plasma at $-70{ }^{\circ} \mathrm{C}$ for 30 days was measured at the LQC and HQC concentrations, difference from freshly prepared samples were $-2.427 \%$ and $4.170 \%$, respectively. When in-injector stability at the LQC and HQC concentrations for 48 hrs at $10{ }^{\circ} \mathrm{C}$ was measured, the differences from freshly prepared samples were low with values $-1.273 \%$ and $-0.280 \%$ respectively. The values are within the acceptance range of \pm 15 $\%$. The results indicate that PPE spiked into human plasma was stable during six freeze thaw cycles, at least $7 \mathrm{hrs}$ at room temperature, $48 \mathrm{hrs}$ at $10{ }^{\circ} \mathrm{C}$ in auto sampler and up to 30 days at around $-70{ }^{\circ} \mathrm{C}$.

The percentage deviation of the mean calculated for PPE in plasma with EDTA was $2.661 \%$ and $1.384 \%$ at LQC and HQC levels, respectively. Whereas, for PPE in plasma with CDPA at LQC and HQC levels are $4.757 \%$ and $4.788 \%$, respectively. The results indicate that the PPE have greater stability in plasma with anticoagulant, EDTA.

\section{CONCLUSION}

A LC-MS method in positive electrospray ionization mode using multiple reaction monitoring is described for the quantification of PPE in human plasma. The developed method was fully validated according to guidelines of United States Food and Drug Administration for validation of bioanalytical methods. The method has shown satisfactory precision and accuracy. The reproducibility, specificity and sufficient sensitivity of this method allows for the selective and reliable determination of PPE in human plasma. Further more this method offers shorter run time over earlier methods.

\section{ACKNOWLEDGEMENT}

One of the authors, P. Lavudu, expresses his gratitude to Dr. Alluri Ramesh, Principal, Vishnu Institute of Pharmaceutical Education \& Research, Narsapur. The author would like to thank Nano Research for Advanced Materials Technologies, Bangalore for facilities to carry out the research work and Andhra Pradesh Vaidya Avidhan Parishad and State Blood Trasfusion Council, Dist HQRS hospital Blood Bank, Sangareddy, Medak district for providing the plasma samples.

\section{References}

[1] Dooley M., Markham A., Drugs \& Aging. 12 (1998) 495-514.

[2] Hoerger T.J., Bala M.V., Rowland C., Greer M., Chrischilles E.A., Holloway R.G., PharmacoEeconomics. 14 (1998) 541-557.

[3] Bennett J.P. Jr., Piercey M.F., J. Neurol. Sci. 163 (1999) 25-31.

[4] Courtney I.J., Jeremy G., Am. Fam. Physician. 75 (2007) 1239-1240.

[5] Inoue Y., Kuroda K., Hirata K., Uchimura N., Kagimura T., Shimizu T., Neuropsychobiology 63 (2011) 35-42.

[6] Lau Y.L., Glenn D.H., Nita I., J. Chromatogr B: Biomed. Sci. Appl. 683 (1996) 217223.

[7] Lau Y.L., Jeffrey M.S., Glenn D.H., Rasmy T., Nita I., J. Chromatogr B: Biomed. Sci. Appl. 683 (1996) 209-216. 
[8] Nirogi R.V., Kandikere V., Shrivastava W., Mudigonda K., Maurya S., Ajjala D., Biomed. Chromatogr. 21 (2007) 1151-1158.

[9] Bharathi D.V., Hotha K.K., Sagar P.V., Kumar S.S., Naidu A., Mullangi R., Biomed. Chromatogr. 23 (2009) 212-220.

[10] Uma G., Manimala M., Vasudevan M., Karpagam S., Deecarman., Int. J. Pharma. Sci. Let. 2 (2012) 10-11.

[11] Guidance for Industry: Bioanalytical Method Validation, U.S. Department of Health and Human Services, Food and Drug Administration, Center for Drug Evaluation and Research (CDER), Center for Biologics Evaluation and Research (CBER), May 2001. 